\title{
Associations between overweight and obesity and health enhancing behaviours among female nurses in Poland
}

\author{
Magdalena Woynarowska-Sołdan ${ }^{1, A, C-F} \oplus$, Mariusz Panczyk ${ }^{2, A-C, E-F} \oplus$, Lucyna Iwanow ${ }^{2, B} \oplus$, \\ Robert Gałązkowski ${ }^{3, E-F} \oplus$, Angelina Wójcik-Fatla ${ }^{4, F} \oplus$, Lech Panasiuk ${ }^{5, F} \oplus$, Joanna Gotlib ${ }^{2, D-F} \oplus$ \\ 1 Public Health Division, Faculty of Health Science, Medical University of Warsaw, Warsaw, Poland \\ 2 Department of Teaching and Outcomes of Education, Faculty of Health Science, Medical University of Warsaw, Warsaw, \\ Poland \\ ${ }^{3}$ Department of Nursing and Emergency Medicine, Institute of Health, Faculty of Natural Science, University of Natural \\ Sciences and Humanities, Siedlce, Poland \\ ${ }^{4}$ Department of Health Biohazards and Parasitology, Institute of Rural Health, Lublin, Poland \\ ${ }^{5}$ Institute of Rural Health, Lublin, Poland \\ A - Research concept and design, B - Collection and/or assembly of data, C - Data analysis and interpretation, \\ $D$ - Writing the article, E - Critical revision of the article, F - Final approval of article
}

Woynarowska-Sołdan M, Panczyk M, Iwanow L, Gałązkowski R, Wójcik-Fatla A, Panasiuk L, Gotlib J. Associations between overweight and obesity and health enhancing behaviours among female nurses in Poland. Ann Agric Environ Med. 2018; 25(4): 714-719. doi: 10.26444/aaem/99641

\begin{abstract}
Introduction and objective. The nursing profession entails many negative factors and high risk of chronic diseases, including overweight and obesity. The aim of the study is to investigate the prevalence of overweight and obesity and health enhancing behaviours in Polish female nurses, and associations between overweight and 4 groups of such behaviours, age and shift work.

Materials and method. The analysis covered data obtained through cross-sectional survey carried out in a group of 994 nurses with an average age of 43 . The analysis covered answers about 29 health-enhancing behaviours divided into 4 categories (subscales): 1) nutrition, 2) physical activity, 3) sleep, rest and behaviours related to mental health, 4) preventive behaviours. They were analysed through the validated Positive Health Behaviours Scale for adults. The analysis also covered answers about avoiding drinking large amounts of alcohol in one go, not smoking, avoiding passive smoking, not abusing unprescribed drugs.

Results. The prevalence of overweight and obesity was 44\%. Of 29 health behaviours concerned with nutrition, physical activity, sleep, rest, and mental health, preventive behaviours, 3 were exhibited always or almost always by over a half of the nurses. Health behaviours were more common in nurses whose BMI was normal than in nurses with $\mathrm{BMI} \geq 25.0$. Age and low physical activity levels were related to overweight and obesity in nurses.

Conclusions. The study revealed a high prevalence of overweight and obesity and many deficits in health behaviours. Obesity and health behaviour deficits pose risks to the health of nurses, limit their involvement in prevention and treatment of patient obesity and impact as health educators. It is essential to engage in actions for health promotion among nurses.
\end{abstract}

Key words

health behaviours, lifestyle, obesity, overweigh, nurses

\section{INTRODUCTION}

In all countries worldwide, nurses constitute the largest group of health care providers. The nursing profession entails a great number of negative factors and health risks associated with the impact of biological, chemical, physical, ergonomic, psychological factors, as well as work organisation and rhythm [1]. Nursing is a profession that entails high stress levels and a great risk of occupational burnout, motor dysfunctions, infectious diseases (tuberculosis, HIV, hepatitis B, C and A), as well as the risk of becoming overweight or obese $[2,3]$.

Overweight and obesity are the most common health problems for nurses. The overweight/obesity rates depend on the region, country, race, ethnic group, age and work mode [4]. In many countries, the prevalence of overweight/obesity

Address for correspondence: Mariusz Panczyk Department of Teaching and Outcomes of Education, Faculty of Health Science, Medical University of Warsaw, Zwirki i Wigry 81, 02-091 Warszawa, Poland

e-mail: mariusz.panczyk@wum.edu.pl

Received: 22.05.2018; accepted: 07.11.2018; first published: 04.12.2018 in nurses is higher compared to the average population. In a study conducted in 2008-2011 in Poland, around 64\% of analysed nurses were found to be overweight/obese [5].

The prevalence of overweight and obesity, including abdominal obesity, is higher in nurses who work in shifts, especially night shifts. The longer the time shift work has been performed, the greater the risk of obesity [6], and the higher the number of night shifts per month, the greater still the obesity risk [5]. This is caused by a number of factors, such as: inadequate nutrition (irregular meal pattern, abnormal eating behaviour, excess sugar consumption, frequent unhealthy snacks), low levels of physical activity, sleep deprivation, negative emotions and increased stress levels $[7,8,9]$.

A variety of factors contribute to overweight and obesity, including metabolic and genetic abnormalities; however, in the overwhelming majority of cases they appear to be primarily linked to an unhealthy lifestyle. Results of numerous studies demonstrate that there are multiple deficiencies in that respect among nurses in various countries. Those deficiencies include: poor nutrition, low physical activity, 
sleep deprivation, few rest breaks, health monitoring and screening below desirable levels, smoking and alcohol abuse $[7,10]$.

Overweight and an unhealthy lifestyle should be viewed in the context of the health of nurses and in the context of their professional role. Overweight increases the risk of cardiovascular diseases, diabetes, diseases of the musculoskeletal system, cancer and premature aging. Obesity in nursing is associated with various functional limitations connected with poor health, limited mobility, flexibility, low endurance, and increased numbers of lost-time injuries in health care, while performing strenuous tasks such as lifting and assisting adult patients [11].

Nurses can also significantly influence patients who try to lose weight and maintain a healthy weight. An obese nurse will fail to be a good role model for the patients in her care. The chance of her success in motivating patients to monitor their weight is limited, especially seeing that more than half of the analysed obese nurses lacked motivation to change their own lifestyle [12]. Nurses provide various groups of patients with formal and informal health education. The deficits in their health behaviours hamper such education and the modelling of positive behaviours in patients.

\section{OBJECTIVE}

The aims of this study was to indicate the prevalence of overweight and obesity as well as health enhancing behaviours among Polish female nurses; to describe relations between overweight and different groups of such behaviours, age and shift work of nurses. The reason for conducting the study was the fact that no such research has been previously undertaken into the relationship between health enhancing behaviours and overweight and obesity rates in nurses in Poland. The present study fills the gap and can serve as a starting point for development of health promotion initiatives aimed at nurses.

\section{MATERIALS AND METHOD}

Study design and population. The study involved a crosssectional survey conducted in May 2016 in a group of female nurses. All professionally active nurses, who participated in a specialization training programme in 2016, were invited to take part in the study. Potential participants were identified and recruited from the Centre for Postgraduate Education for Nurses and Midwives in Warsaw, Poland. The cohort consisted of 2,542 registered nurses, with a return rate of $40 \%$. Thus, 994 participants took part in the study. The cohort was representative in terms of the mean age $(\mathrm{t}=0.824 ; P=0.426)$ and the selected specialization $\left(\chi^{2}=0.046 ; P=0.831\right)$. With this cohort size and the number of registered nurses working in Poland $(\mathrm{N}=280,000)$, the error margin was 3.2\% $(95 \%$ confidence level and proportion 0.50).

Participation in the study was voluntary and anonymous. Results were collected using an auditorium method (selfreport questionnaire), whereby respondents filled in the questionnaires individually in one room. By virtue of the large number of participants in the study, the random survey was conducted in 20 turns. The place and procedure of the study was identical each time.
Table 1 reports the demographic characteristics of the 994 participants who completed the study. Mean age of the study participants -43.1 years $(\mathrm{SD}=7.21)$; professional experience -20.0 years $(\mathrm{SD}=8.45)$.

Table 1. Sociodemographic characteristics of the study sample $(\mathrm{N}=994)$.

\begin{tabular}{lc}
\hline & $\mathbf{N}(\%)$ \\
\hline Place of residence & $288(29.0)$ \\
Countryside & $212(21.3)$ \\
Village (population up to 50 thousand) & $204(20.5)$ \\
Small town (51-200 thousand inhabitants) & $147(14.8)$ \\
Large town (201-500 thousand inhabitants) & $143(14.4)$ \\
City >500 thousand inhabitants & \\
\hline Education & $271(27.3)$ \\
Secondary medical & $298(30.0)$ \\
Bachelor's degree & $419(42.2)$ \\
Master's degree & $6(0.5)$ \\
Ph.D. & \\
\hline Specialisation & $180(18.3)$ \\
Conservative nursing & $172(17.5)$ \\
Anaesthesiological nursing & $132(13.4)$ \\
Surgical nursing & $89(9.0)$ \\
Operating room nursing & $55(5.6)$ \\
Psychiatric nursing & $48(4.9)$ \\
Cardiological nursing & $48(4.9)$ \\
Neonatal nursing & $46(4.7)$ \\
Obstetric nursing & $43(4.4)$ \\
Epidemiological nursing & $43(4.4)$ \\
Geriatric nursing & $138(13.9)$ \\
Other & \\
\hline Place of work' & $725(72.9)$ \\
Municipal hospital & $269(27.1)$ \\
Clinical hospital & $385(32.8)$ \\
Home care & $212(18.1)$ \\
General practitioner outpatient clinic & $201(17.1)$ \\
Specialised outpatient clinic & $57(4.0)$ \\
Environmental care & $50(4.3)$ \\
Other & $197(16.8)$ \\
\hline Shift work & \\
Yes & \\
\hline No & \\
\hline Studpatipantscould & \\
\hline
\end{tabular}

1 Study participants could indicate more than one place of work

Ethics Statement. According to the Bioethics Committee 'non-interventional studies do not require the opinion of the Bioethics Committee, in accordance with Art. 37al Pharmaceutical Law Act (Journal of Laws 2001, No. 126, item 1381).

\section{OBJECTIVES}

The objective of the study and its anonymity throughout the research process and the voluntary nature of their participation were explained face-to-face to participants before administration of the questionnaire, and their informed consent was obtained. They were also informed that the study was for research purposes only, and that the findings were to be limited to research-oriented purposes. Information about the details of the study, data collection and analysis, names of the researchers and contact information were also included.

Variables. 1) Health enhancing behaviours. The analysis covered answers about 29 health enhancing behaviours divided into 4 categories (subscales): 1) nutrition, 2) physical 
activity, 3) sleep, rest and behaviours related to mental health, and 4) preventive behaviours. They were analysed through the validated Positive Health Behaviours Scale for adults [13]. The respondents defined the frequency of engaging in those behaviours on a 4-point scale: always or almost always (3 points), often (2 points), sometimes (1 point), never or almost never (0 points). The correct (desired) answer was always or almost always. Cronbach's alpha was 0.844 for the full scale, and $0.623-0.761$ for particular subscales. The result was deemed satisfactory.

2) Avoiding risk behaviours. Avoiding health-compromising behaviours counted as a health positive behaviour and an element of a healthy lifestyle. The analysis covered answers about avoiding drinking large amounts of alcohol in one go, not smoking, avoiding passive smoking, not abusing unprescribed drugs. The statements were formulated in such a way so as to define desirable, health-conscious behaviours. If a given statement was true for the respondent, they marked the box: I do it.

3) Body Mass Index. The height and weight details provided by the respondents (self-reported data) were used to calculate the Body Mass Index (BMI). The nurses were classified into 5 groups: underweight, healthy weight, overweight, first degree of obesity, second and third degree of obesity [14]. Two groups of respondents were included in the analyses of relationships between overweight and obesity and the health enhancing behaviours: respondents with a healthy weight (BMI 18.5-24.99; $\mathrm{N}=548$ ) and respondents with overweight and obesity ( $\mathrm{BMI} \geq 25.00 ; \mathrm{N}=434)$. Underweight respondents were not included in the analyses due to their small numbers $(\mathrm{N}=12)$.

4) Shift work. The fact of whether or not the respondents performed shift work was included in the analyses based on self-reported data.

Statistical analysis. All statistical analyses were performed in STATISTICA 13.1 (StatSoft ${ }^{\odot}$, Inc.) under the licence held by the Medical University of Warsaw. The relationship between the age of respondents and BMI values was estimated by means of Jonckheere-Terpstra test for ordered alternatives. The significance of differences between the respondents with a healthy weight and the respondents with overweight or obesity was evaluated with Pearson's chi-square test. The impact of particular behaviours on the overweight/obesity rates was determined through computation of odds ratio (OR) with 95\% confidence intervals. Logistic regression was applied to analyse the factors that predispose to overweight/ obesity. The proposed logistic model examined 6 potential predictors: age, shift work, number of points for each of the 4 subscales of health enhancing behaviours. The modelled dependent variable was the occurrence of overweight or obesity (BMI $\geq 25.00$ ). The Rosenbrock and Quasi-Newton methods were employed, with specification of asymptotic standard errors. The goodness of fit of data with the proposed logit function was assessed by the Hosmer-Lemeshow test. P-values $<0.05$ were considered statistically significant.

\section{RESULTS}

Prevalence of overweight and obesity among nurses. The average BMI in the analysed group was 25.1 ( \pm 4.36$)$. Among the respondents, a min. of 16.3 and max. of 67.2 . $44 \%$ were
Table 2. Analysed nurses $(\mathrm{N}=994)$ according to BMI, age and shift work

\begin{tabular}{lcccccc}
\hline \multirow{2}{*}{ BMI $\left(\mathrm{kg} / \mathrm{m}^{2}\right)$} & \multicolumn{2}{c}{ Respondents } & \multicolumn{2}{c}{ Age (years) } & \multicolumn{2}{c}{ Shift work (\%) } \\
\cline { 2 - 8 } & $N$ & $\%$ & Mean & SD & Yes & No \\
\hline$<18.5$ underweight & 12 & 1.2 & 39.3 & 7.96 & 25.0 & 75.0 \\
\hline $18.5-24.99$ normal range & 548 & 55.1 & 41.8 & 7.48 & 27.5 & 72.5 \\
\hline $25.00-29.99$ pre-obese & 323 & 32.5 & 44.7 & 6.35 & 28.7 & 71.3 \\
\hline $30.00-34.99$ obese class I & 87 & 8.8 & 45.6 & 6.61 & 20.7 & 79.3 \\
\hline$>35.00$ obese class II and III & 24 & 2.4 & 45.8 & 6.70 & 25.0 & 75.0 \\
\hline & & & $P<0.001^{*}$ & $P=0.674^{* *}$ \\
\hline
\end{tabular}

* Jonckheere-Terpstra test

** Pearson's chi-square test

found to be overweight or obese, with only $1 \%$ of the nurses were underweight (Tab. 2). As the age of the respondents increased, so did the BMI values (Jonckheere-Terpstra test, $P<000.1)$. Most of the respondents $(73 \%)$ worked in shifts - the share of respondents who worked in shifts was comparable in particular BMI groups $\left(\chi^{2}=2.34, \mathrm{df}=4 ; P=0.674\right)$.

Health enhancing behaviours among nurses. In the entire analysed group, of the 29 health behaviours included in the questionnaire only 3 were adhered to with the desired frequency, i.e. always or almost always (Tab. 3), by more than a half of the nurses (brushing teeth at least twice a day - 82.2\%; measuring blood pressure - $61.2 \%$; having smear tests $-55.4 \%)$. The lowest percentage included nurses who coped well with stress (6.6\%), avoided snacking (9.1\%), spent at least 20-30 minutes a day resting/relaxing (9.6\%).

The nurses with a healthy weight engaged in significantly more health enhancing behaviours (25/29) with desired frequency. Statistically significant differences were identified in the case of 11 analysed behaviours: 5 of them applied to nutrition, 4 (all) applied to physical activity, and 2 applied to oral hygiene. 5 of those behaviours were found to be especially important in significantly reducing the risk of overweight/ obesity: limiting the intake of animal fats (OR=0.49; CI [0.34-0.71]), increasing physical activity and physical effort in everydaylife $(\mathrm{OR}=0.50 ; \mathrm{CI}[0.36-0.71])$, performing strengthbuilding exercises for the main muscle groups at least twice a week $(\mathrm{OR}=0.52$; $\mathrm{CI}$ [0.36-0.75]), exercising daily for at least 30 min. with moderate or vigorous intensity $(\mathrm{OR}=0.53$; $\mathrm{CI}$ [0.34-0.82]), and limiting the time spent watching television $(\mathrm{OR}=0.56$; CI [0.39-0.81]) (Tab. 3).

Avoiding risk behaviours. The majority of respondents did not engage in any risk behaviours named in the questionnaire. The results were least positive in the area of active and passive smoking (Tab. 4). The differences between groups divided according to BMI values were not statistically significant.

Factors that predispose nurses to overweight and obesity. The proposed logistic regression model was statistically significant $\left(\chi^{2}=69.6 ; P<0.001 ;\right.$ R-squared Nagelkerke $\left.=0.092\right)$, and the logit function was adequate (Hosmer-Lemeshow test: $12.7 ; P=0.124)$. Estimation of function parameters revealed that only 2 predictors - age and physical activity level - were important factors that predisposed nurses to overweight/ obesity. The risk of overweight/obesity grew significantly with the age of the respondents $(\mathrm{OR}=1.067$; Wald test $=42.6$; $P<0.001)$. The respondents who obtained high scores in the 
Table 3. Health enhancing behaviours taken with desired frequency (i.e. always or almost always): total and according to BMI (\%).

Behaviours Total $\frac{\mathrm{BMI}}{18.5-24.99 \quad \geq 25.00}$ OR $^{*} \quad 95 \% \mathrm{Cl} \quad \mathrm{P}^{* *}$

\section{Nutrition}

Having at least 3 meals a day with a regular meal pattern

\begin{tabular}{cccccc}
36.9 & 39.8 & 33.3 & 0.76 & $0.58-0.98$ & 0.036 \\
\hline 46.0 & 46.9 & 44.9 & 0.92 & $0.71-1.18$ & NS \\
\hline 44.5 & 46.5 & 41.7 & 0.82 & $0.63-1.06$ & NS \\
\hline 39.0 & 42.0 & 34.8 & 0.74 & $0.57-0.96$ & 0.021 \\
\hline 13.4 & 15.8 & 9.7 & 0.57 & $0.34-0.84$ & 0.005 \\
\hline 15.4 & 19.1 & 10.4 & 0.49 & $0.34-0.71$ & $<0.001$ \\
\hline 19.1 & 21.1 & 16.1 & 0.72 & $0.52-0.99$ & 0.048 \\
\hline 13.6 & 14.7 & 12.2 & 0.81 & $0.56-1.17$ & NS \\
\hline 9.1 & 10.4 & 7.9 & 0.74 & $0.47-1.15$ & NS
\end{tabular}

Having breakfast at home every morning (more than a glass of milk, tea or other beverage)

Eating fruits at least once a day

Eating vegetables at least once a day

Drinking at least 2 glasses of milk, kefir or yoghurt daily

Limiting the intake of animal fats

Limiting the intake of salt

Limiting the amount of consumed sweets

Avoiding snacks between meals

\section{Physical activity}

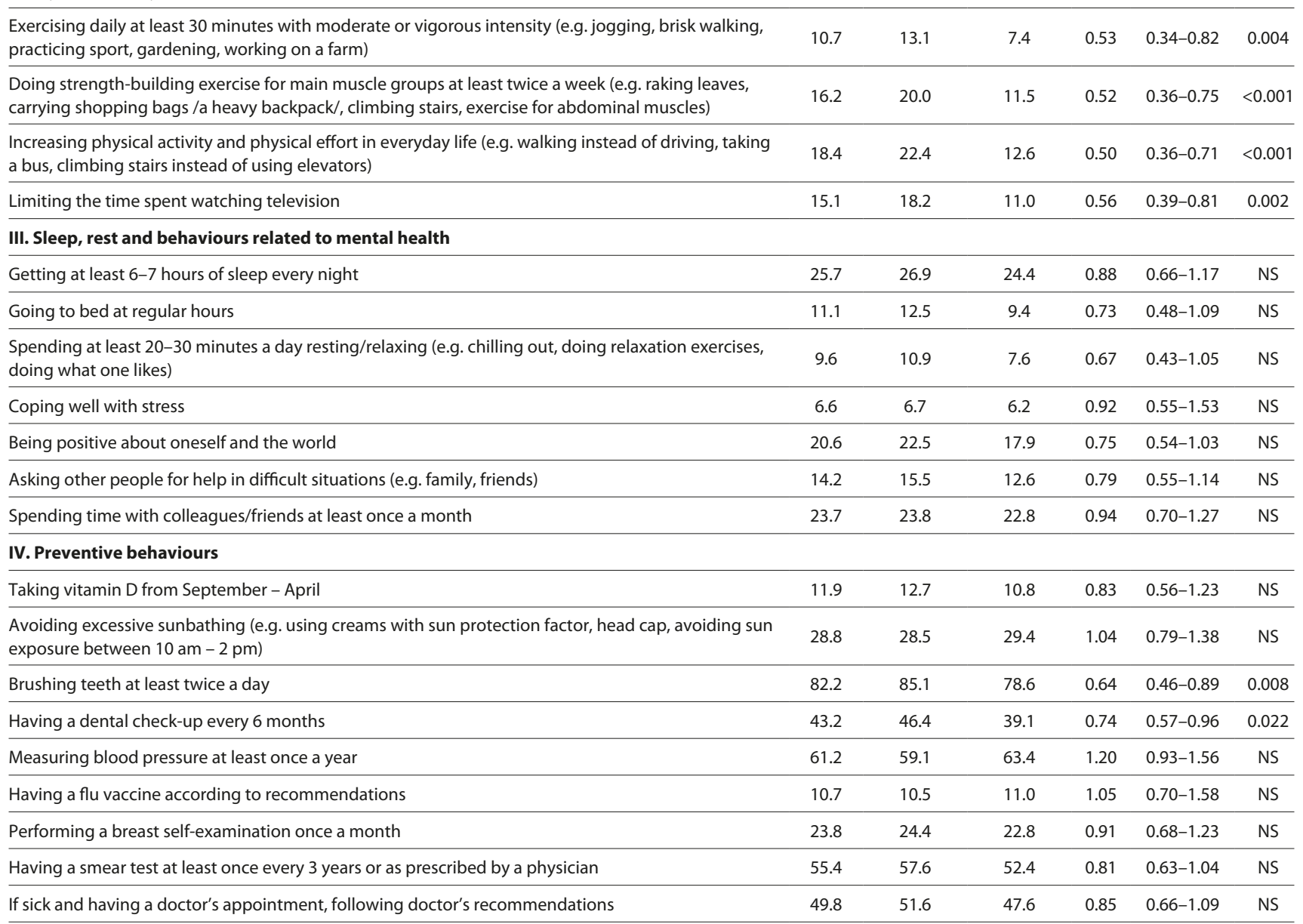

* odds ratio ( $O R<1.00$ lower risk of overweight, $O R>1.00$ higher risk of overweight)

** Pearson's chi-squared test

$95 \% \mathrm{Cl}-95 \%$ confidence interval, NS - statistically insignificant

Table 4. Avoiding risk behaviours: total and according to BMI (\%)

\begin{tabular}{|c|c|c|c|c|c|c|}
\hline \multirow{2}{*}{ Behaviours } & \multirow{2}{*}{ Total } & \multicolumn{2}{|c|}{ BMI } & \multirow{2}{*}{$O R^{*}$} & \multirow{2}{*}{$95 \% \mathrm{Cl}$} & \multirow{2}{*}{$P^{* *}$} \\
\hline & & $18.5-24.99$ & $\geq 25.00$ & & & \\
\hline Not drinking large amounts of alcohol in one go (not becoming inebriated) & 81.4 & 80.6 & 82.8 & 1.15 & $0.84-1.61$ & NS \\
\hline Not smoking & 70.9 & 72.7 & 68.5 & 0.81 & $0.62-1.07$ & NS \\
\hline Avoiding passive smoking & 64.5 & 65.8 & 62.5 & 0.87 & $0.67-1.13$ & NS \\
\hline Not abusing drugs not prescribed by physicians (painkillers, sedatives, sleeping pills) & 78.9 & 78.7 & 78.9 & 1.01 & $0.74-1.37$ & NS \\
\hline
\end{tabular}

* odds ratio ( $\mathrm{OR}<1.00$ lower risk of overweight, $\mathrm{OR}>1.00$ higher risk of overweight)

** Pearson's chi-squared test

$95 \% \mathrm{Cl}-95 \%$ confidence interval, NS - statistically insignificant 
Table 5. Odds ratios (OR) with $95 \%$ confidence intervals of shift-work, age, and points in 4 subscales of health behaviours for the prevalence of overweight and obesity in female nurses $(\mathrm{N}=994)$

\begin{tabular}{|c|c|c|c|c|c|c|}
\hline \multirow[t]{2}{*}{ Predictors } & \multirow{2}{*}{$\begin{array}{l}\text { Effect } \\
\text { size* }\end{array}$} & \multirow{2}{*}{$\begin{array}{l}\text { Odds } \\
\text { ratio }\end{array}$} & \multicolumn{2}{|c|}{$\begin{array}{l}95 \% \text { confidence } \\
\text { interval }\end{array}$} & \multirow{2}{*}{$\begin{array}{c}\text { Wald } \\
\text { test }\end{array}$} & \multirow[t]{2}{*}{ P-value } \\
\hline & & & Lower & Upper & & \\
\hline Intercept & -1.406 & 0.245 & 0.067 & 0.893 & 4.545 & 0.033 \\
\hline $\begin{array}{l}\text { Shift work } \\
0: \text { no } \\
1: \text { yes }\end{array}$ & 0.152 & 1.165 & 0.860 & 1.577 & 0.971 & 0.324 \\
\hline Age [years] & 0.065 & 1.067 & 1.047 & 1.088 & 42.621 & $<0.001$ \\
\hline Nutrition & -0.003 & 0.997 & 0.981 & 1.013 & 0.128 & 0.720 \\
\hline Physical activity & -0.029 & 0.972 & 0.957 & 0.987 & 13.347 & $<0.001$ \\
\hline $\begin{array}{l}\text { Sleep, relaxation and } \\
\text { behaviours related to } \\
\text { mental health }\end{array}$ & -0.001 & 0.999 & 0.984 & 1.014 & 0.024 & 0.876 \\
\hline Preventive behaviours & -0.003 & 0.997 & 0.983 & 1.012 & 0.114 & 0.736 \\
\hline
\end{tabular}

physical activity subscale were less likely to be overweight or obese, compared to the respondents with low scores $(\mathrm{OR}=0.972$; Wald test $=13.3 ; P<0.001)($ Tab. 5$)$.

\section{DISCUSSION}

This study presents results of a survey on overweight and obesity and health enhancing behaviours conducted in a large group $(\mathrm{N}=994)$ of nurses in Poland. The nurses were preparing for the State specialty examination in various specialties. Most of them (73\%), worked in shifts.

The prevalence of overweight and obesity was assessed via BMI values based on self-reported height and weight details. The use of this method was dictated by the results of research conducted by other authors. In the group of Polish nurses, the comparison of self-reported body weight and height with measured values showed high correlations and tendency for underreporting weight, particularly by heavier women, and over-reporting height by shorter women [5]. In a general US population, the discrepancies between self-reported and measured obesity were insignificant, with self-reported data underestimating measured prevalence by about $3 \%$, and they remained relatively constant over time [15].

About $44 \%$ of female nurses were found to be obese or overweight. Their rates increased with age and were similar to the rates recorded in an average population of Polish women where they oscillated around $32 \%$ in a group of women aged $30-39$, and around $60 \%$ in a group of women aged $50-59$. Nonetheless, obesity and overweight were more common among nurses than in an average population of women with higher education aged above 15 (32\%) [16]. In the analysed group, the percentage of overweight nurses was lower than that in Australia (60\%) [17], Scotland (69\%) [18], and the USA (49\%) [19], and that recorded in a previous study conducted in Poland (64\%) [5].

As a part of the survey, 4 groups of health behaviours were analysed: nutrition; physical activity; sleep, rest, and behaviours related to mental health; preventive behaviours. Of the 29 behaviours, only 3 were taken with the desired frequency (always or almost always) by more than a half of the nurses, and 9 behaviours were declared by fewer than $15 \%$ of the respondents. Nearly one in 3 nurses smoked or were exposed to second-hand smoke, one in 5 abused alcohol and drugs not prescribed by a physician.

One of the expectations about the research was that health enhancing behaviours in nurses - individuals who received medical education and raise their qualifications under specialty programmes, should be common. The results, however, failed to meet the expectations. The numerous deficits identified in the lifestyles led by nurses are alarming on account of the health of this professional group, and on account of the patients, as the deficits may compromise their safety. Nurses who, as a part of their job, provide health education, cannot act as role models for patients, which means that the education will be less effective.

Deficits in health behaviours of nurses are a common problem in a number of countries. They include inadequate diet, low level of physical activity [20, 21, 22, 23, 24], not enough sleep and rest [25], health monitoring and screening below desirable levels [22]. In addition, nurses engage in a number of risky behaviours - smoking tobacco and alcohol abuse $[25,26,27]$. A comparison of deficits in health behaviours of nurses in various countries is not feasible due to the differences in applied research methods.

Overweight and obese nurses in the current study had far more deficiencies in terms of health behaviours than nurses whose BMI was within normal range. No differences were found between particular groups in terms of frequency of unhealthy behaviours. The greatest number of differences applied to physical activity levels and nutrition. These behaviours could predispose the analysed nurses to overweight.

No relation was found between overweight and shift work; therefore, the results of most research studies conducted so far have not been confirmed. This might be due to an overly general nature of the question about shift work, which did not highlight the shift pattern nor specify the time of working in shifts. In other research studies, a correlation was found between rotating night shift work and abdominal obesity [5]. A significant positive association between obesity and shift work duration was found among Korean nurses [28]. In Australia, rotating shifts of nurses were associated with both overweight and obesity, while night shifts were associated with obesity but not overweight [17]. The results prove the need for a more detailed description of a work schedule.

The results demonstrate that the nursing profession in Poland entails a high risk of overweight and obesity, as well as other health problems related to lifestyle. The results should be viewed in a wider context of the unfavourable working conditions of this professional group, made up mostly of women (98\%), in Poland [29]. Currently, the group is ageing - the mean age of Polish nurses is 48.4 years of age and it has been systematically increasing throughout the years. There are insufficient numbers of nurses in relation to the size of the population: statistically 48 per 1,000 people [30]; in an OECD ranking, Poland ranks almost at the bottom in that respect [31]. This results in increased workloads: $95 \%$ of nurses are not able to fulfil all their duties within their nominal work hours, $53 \%$ are asked to do extra work, and one in $25 \%$ have been alone on hospital duty at least once during the last 3 months [32]. The economic status of nurses is low - their average wage constitutes $84 \%$ of the national average wage [33], their salary is twice as low as that of doctors [32]. Nurses sense that their salaries are too low in relation to the amount of work they do, which is why they organise protests and why younger nurses leave to work abroad [30]. Large numbers 
of nurses take extra jobs that make their work hours even longer, increase workloads, fatigue, and make it even more difficult to engage in health behaviours.

While interpreting the findings, one should also take into consideration the limitations of the study. One limitation is the choice of the sample that included nurses who were working on increasing their professional qualifications. Perhaps the additional work they had to devote to prepare for the specialty exam had a negative impact on their lifestyle. In addition, all the data was self-reported, and the incidence of overweight and unhealthy behaviours might have been underestimated while healthy behaviours could have been overestimated. The research should be continued in other groups of nurses.

\section{CONCLUSIONS}

Despite the above-mentioned limitations, this cross-sectional study demonstrates a high prevalence of overweight and obesity among Polish female nurse, and obesity rates in this group are even higher than in a general population. There is a great risk that the rates will become even higher as a result of numerous deficiencies in health behaviours identified within the group. The greatest deficits were identified in the area of physical activity, nutrition, coping with stress, and rest. The age and low level of physical activity especially bore a significant relation to overweight and obesity. Obesity and deficits in health behaviours pose a risk to nurses' health and limit their efficiency in preventing and treating obesity in patients, and their impact as health educators. The situation calls for intensification of education of nursing professionals in the area of health-conscious lifestyles, obesity management and prevention, as well as implementation of interventional health promotion programmes aimed at nurses at the workplace.

\section{REFERENCES}

1. Canadian Centre for Occupational Health and Safety. Nurse (Registered), [Online]. 2013 [cited 2016 Oct 12]; Available from: URL: http://www.ccohs.ca/oshanswers/occup_workplace/nurse.html

2. Adriaenssens J, De Gucht V, Maes S. Determinants and prevalence of burnout in emergency nurses: a systematic review of 25 years of research. Int J Nurs Stud. 2015; 52: 649-661.

3. Fronteira I, Ferrinho P. Do nurses have a different physical health profile? A systematic review of experimental and observational studies on nurses' physical health. J Clin Nurs. 2011; 20: 2404-2424.

4. Buss J. Associations between obesity and stress and shift work among nurses. Workplace Health Saf. 2012; 60: 453-458.

5. Peplonska B, Bukowska A, Sobala W. Association of Rotating Night Shift Work with BMI and Abdominal Obesity among Nurses and Midwives. PLoS One 2015; 10: e0133761.

6. Lee G-J, Kim K, Kim S-y, Kim J-H, Suh C, Son B-C, Lee C-K, Choi J. Effects of shift work on abdominal obesity among 20-39-year-old female nurses: a 5-year retrospective longitudinal study. Ann Occup Environ Med. 2016; 28: 69.

7. Heath G, Roach GD, Dorrian J, Ferguson SA, Darwent D, Sargent C. The effect of sleep restriction on snacking behaviour during a week of simulated shiftwork. Accid Anal Prev. 2012; 45 Suppl: 62-67.

8. Lowden A, Moreno C, Holmback U, Lennernas M, Tucker P. Eating and shift work - effects on habits, metabolism and performance. Scand J Work Environ Health 2010; 36: 150-162.

9. Wong H, Wong MC, Wong SY, Lee A. The association between shift duty and abnormal eating behavior among nurses working in a major hospital: a cross-sectional study. Int J Nurs Stud. 2010; 47: 1021-1027.

10. Geiger-Brown J, Rogers VE, Han K, Trinkoff A, Bausell RB, Scharf SM: Occupational screening for sleep disorders in 12-h shift nurses using the Berlin Questionnaire. Sleep Breath 2013; 17: 381-388.
11. Jordan G, Nowrouzi-Kia B, Gohar B, Nowrouzi B. Obesity as a Possible Risk Factor for Lost-time Injury in Registered Nurses: A Literature Review. Saf Health Work 2015; 6: 1-8.

12. Miller SK, Alpert PT, Cross CL. Overweight and obesity in nurses, advanced practice nurses, and nurse educators. J Am Acad Nurse Pract. 2008; 20: 259-265.

13. Woynarowska-Sołdan M, Węziak-Białowolska D. Psychometric analysis of Positive Health Behaviours Scale for adults. Probl Hig Epidemiol. 2012; 93: 369-376.

14. World Health Organization. The International Classification of adult underweight, overweight and obesity according to BMI, [Online]. 2006 [cited 2017 Feb 10]; Available from: URL: http://apps.who.int/bmi/ index.jsp?introPage=intro_3.html

15. Connor Gorber S, Tremblay MS. The bias in self-reported obesity from 1976 to 2005: a Canada-US comparison. Obesity (Silver Spring, Md) 2010; 18: 354-361.

16. Central Statistical Office of Poland: Health status of population in Poland in 2014, [Online]. 2016 [cited 2017 Feb 10]; Available from: http://stat.gov.pl/obszary-tematyczne/zdrowie/zdrowie/stan-zdrowialudnosci-polski-w-2014-r-,6,6.html

17. Zhao I, Bogossian F, Turner C. A cross-sectional analysis of the association between night-only or rotating shift work and overweight/ obesity among female nurses and midwives. J Occup Environ Med. 2012; 54: 834-840.

18. Kyle RG, Neall RA, Atherton IM. Prevalence of overweight and obesity among nurses in Scotland: A cross-sectional study using the Scottish Health Survey. Int J Nurs Stud. 2016; 53: 126-133.

19. Chin DL, Nam S, Lee SJ. Occupational factors associated with obesity and leisure-time physical activity among nurses: A cross sectional study. Int J Nurs Stud. 2016; 57: 60-69.

20. Zapka JM, Lemon SC, Magner RP, Hale J. Lifestyle behaviours and weight among hospital-based nurses. J Nurs Manag. 2009; 17: 853-860.

21. Tucker SJ, Harris MR, Pipe TB, Stevens SR. Nurses' ratings of their health and professional work environments. AAOHN J 2010; 58: 253-267.

22. Perry L, Gallagher R, Duffield C: The health and health behaviours of Australian metropolitan nurses: an exploratory study. BMC Nurs. 2015; 14: 45.

23. Witkoski A, Dickson VV. Hospital staff nurses' work hours, meal periods, and rest breaks. A review from an occupational health nurse perspective. AAOHN J 2010; 58: 489-497.

24. Phiri LP, Draper CE, Lambert EV, Kolbe-Alexander TL. Nurses' lifestyle behaviours, health priorities and barriers to living a healthy lifestyle: a qualitative descriptive study. BMC Nurs. 2014; 13: 38.

25. Han K, Trinkoff AM, Storr CL, Geiger-Brown J, Johnson KL, Park S. Comparison of job stress and obesity in nurses with favorable and unfavorable work schedules. J Occup Environ Med. 2012; 54: 928-932.

26. Marquezea EC, Lemosa LC, Soaresa N, Lorenzi-Filhob G, Morenoa CR. Weight gain in relation to night work among nurses. Work 2012; 41: 2043-2048

27. Bakhshi S, Sun F, Murrells T, While A. Nurses' health behaviours and physical activity-related health-promotion practices. Br J Community Nurs. 2015; 20: 289-296.

28. Kim MJ, Son KH, Park HY, Choi DJ, Yoon CH, Lee HY, Cho EY, Cho MC. Association between shift work and obesity among female nurses: Korean Nurses' Survey. BMC Public Health 2013; 13: 1204.

29. Centre for Healthcare Information Systems. Statistical Bulletin of Ministry of Health, [Online]. Warsaw (Poland): Ministry of Health Republic of Poland; 2016 [cited 2016 Nov 5]; Available from: URL https://www.csioz.gov.pl/fileadmin/user_upload/biuletyn_ statystyczny_2016_57ee354e48145.pdf

30. Main Chamber of Nurses and Midwives: Securing the Services of Nurses and Midwives within the Polish society. A Report of the Main Chamber of Nurses and Midwives, [Online]. 2015 [cited 2016 Nov 5]; Available from: http://arch.nipip.pl/attachments/article/3368/ Raport_2015_NIPiP.pdf

31. Organisation for Economic Co-operation and Development. Nurses (indicator) 2014, [Online]. 2017 [cited 2017 March 30]; Available from: URL: https://data.oecd.org/healthres/nurses.htm

32. National Trade Union of Nurses and Midwives. Employment and working conditions of nurses and midwives in Poland, [Online]. 2015 [cited 2016 Nov 10]; Available from: URL: http://ozzpip.pl/wp-content/ uploads/2015/05/Raport-ko\%C5\%84cowy_ankiety.pdf

33. Hajec M. Nurse salaries in Poland, [Online]. 2015 [cited 2016 Nov 5]; Available from: URL: http://wynagrodzenia.pl/artykul/wynagrodzeniapielegniarek-w-polsce 